\title{
Analysis of Novel Nonviral Gene Transfer Systems for Gene Delivery to Cells of the Musculoskeletal System
}

\author{
Patrick Orth · Anja Weimer · Gunter Kaul - Dieter Kohn · Magali Cucchiarini · \\ Henning Madry
}

Published online: 17 October 2007

(c) Humana Press Inc. 2007

\begin{abstract}
The aim of the present study was to evaluate the efficacy of novel nonviral gene delivery systems in cells of musculoskeletal origin. Primary cultures of lapine skeletal muscle cells, lapine articular chondrocytes, human cells from fibrous dysplasia and cell lines established from human osteosarcoma (SAOS-2), chondrosarcoma (CS-1), murine skeletal myoblasts (L8) and fibroblasts (NIH 3T3) were transfected with the $P$. pyralis luc or the E. coli lacZ genes using Nanofectin 1 and 2, Superfect, JetPEI, GeneJammer, Effectene, TransPass D2, FuGENE 6, Lipofectamine 2000, Dreamfect, Metafectene, Escort III, and calcium phosphate. Maximal transfection efficiency in lapine skeletal muscle cells was of $60.8 \pm 21.2 \%$ using Dreamfect, $38.9 \pm 5.0 \%$ in articular chondrocytes using Gene Jammer, $5.2 \pm 8.0 \%$ in human cells from fibrous dysplasia using Lipofectamine 2000, $12.7 \pm 16.2 \%$ in SAOS-2 cells using FuGENE 6, $29.9 \pm 3.5 \%$ in CS-1 cells using Lipofectamine 2000, $70.7 \pm 8.6 \%$ in L8 cells using FuGENE 6, and $48.9 \pm 13.0 \%$ in NIH 3T3 cells using Metafectene. When the cells were transfected with a human IGF-I gene, significant amounts of the IGF-I protein were secreted. These results indicate that relatively high levels of transfection can be achieved using novel nonviral gene transfer methods.
\end{abstract}

Keywords Gene transfer - Nonviral .

Musculoskeletal cells · IGF-I · Transfection efficiency

P. Orth · A. Weimer · G. Kaul · D. Kohn · M. Cucchiarini ·

H. Madry $(\square)$

Laboratory for Experimental Orthopaedics, Department of Orthopaedic Surgery, Saarland University Medical Center, Building 37, Kirrbergerstr. 1, 66421 Homburg, Germany

e-mail: hmad@hotmail.com

\section{Introduction}

Gene transfer to cells that constitute the musculoskeletal system is a valuable tool for functional studies and possible therapeutic applications such as gene-modified tissue regeneration. Although it has been shown that these cells can be transduced with viral vectors at high efficiencies [1], these vectors carry the risk of insertional mutagenesis (retroviral vectors), immunogenicity (adenoviral vectors) and acquisition of replication competence [1]. Nonviral gene delivery systems are potent alternatives that may overcome such crucial issues [2]. They usually do not provoke an immune response, are relatively easy to manipulate and show no limitation in the size of DNA to be delivered. Transfection of articular chondrocytes and skeletal muscle cells has been already reported using typical transfection methods [3, 4]. Recently, however, novel nonviral gene delivery systems have been developed [2], including activated-dendrimer [5], linear polyethylenimine [6], lipid- [7] and nanoparticlebased compounds [8]. Although these new systems hold promises to achieve high-transfection efficiencies, a systematic evaluation in a large variety of cells has not, to our knowledge, been performed to date.

The aim of this study was to comparatively examine a panel of novel nonviral compounds in both primary cells and established cell lines from musculoskeletal origin. We tested the hypothesis that, under optimized conditions, these gene transfer systems are capable of yielding high transfection efficiencies. We chose 13 systems that are based on nanoparticles, activated-dendrimers, linear polyethylenimines and several lipid-based compounds and cationic liposomes. All of them were tested in primary cultures of skeletal muscle cells, articular chondrocytes, cells from fibrous dysplasia and cell lines from osteosarcoma (SAOS-2), chondrosarcoma (CS-1), myoblasts (L8) and fibroblasts (NIH 3T3). For each 
cell type, the transfection system promoting the highest efficiency was next applied, in order to monitor the secretion levels of the transgene product. For this purpose, a human insulin-like growth factor I (IGF-I) plasmid expression vector was used.

\section{Materials and Methods}

Materials

Reagents were from Invitrogen (Karlsruhe, Germany) unless otherwise indicated. Plasticware was from Falcon (Beckton Dickinson, Pont de Claix, France). For transfections, Nanofectin 1 and 2 (PAA, Pasching, Austria), Superfect (Qiagen, Hilden, Germany), JetPEI (PolyPlus Transfection, Illkirch, France), Escort III (Sigma, Taufkirchen, Germany), Gene Jammer (Stratagene, La Jolla, CA), Effectene (Qiagen), TransPass D2 (New England Biolabs, Ipswich, MA), FuGENE 6 (Roche, Mannheim, Germany), Lipofectamine 2000 (Invitrogen), Metafectene (Biontex, Munich, Germany), and Dreamfect (Oz Bioscience, Marseille, France) were used.

\section{Cell Culture}

Primary cells used in this study included lapine skeletal muscle cells and articular chondrocytes and human cells from fibrous dysplasia. Established cell lines were SAOS-2 (human osteosarcoma), CS-1 (human chondrosarcoma), L8 (murine skeletal myoblasts), and NIH 3T3 cells (murine fibroblasts). Cells were cultured at $37^{\circ} \mathrm{C}$ in a humidified atmosphere with $5 \% \mathrm{CO}_{2}$. Lapine articular chondrocytes were obtained from cartilage of the knee joints of male Chinchilla bastard rabbits as previously described [9]. Lapine muscle was obtained from the quadriceps muscle of male Chinchilla bastard rabbits. Pieces of $0.5 \mathrm{~cm}^{3}$ were removed after sacrifice and transferred to a spinner bottle containing DMEM with $50 \mu \mathrm{g} / \mathrm{ml}$ ascorbic acid, $100 \mathrm{U} / \mathrm{ml}$ penicillin $\mathrm{G}$ and $100 \mathrm{ml} / \mathrm{ml}$ streptomycin (basal medium) with collagenase $(0.05 \%)$ for $20 \mathrm{~h}$. Cells were filtered through a $40-\mu \mathrm{m}$ cell strainer to remove undigested matrix. Cells from human fibrous dysplasia were obtained from tissue removed during tumor surgery of the proximal femur from a 23-year-old patient after digestion for $16 \mathrm{~h}$ in basal medium containing $0.2 \%$ collagenase. All cells were placed in monolayer culture in DMEM with $10 \%$ FBS (growth medium) in 24-well plates. Transfections were performed at $60-70 \%$ cell confluence.

\section{Plasmid DNA}

Plasmid expression vectors carried either the Photinus pyralis luciferase gene (pCMVLuc), the Escherichia coli
lacZ gene (pCMVlacZ) or the human IGF-I gene (pCMVhIGF-I) under the control of the CMV-IE promoter/ enhancer. Vectors were propagated in competent E. coli cells (TOP 10 One Shot, Invitrogen). Ultrapure endotoxinfree plasmid DNA was prepared using the Qiagen Endofree Plasmid Maxi Kit according to the manufacturer's instructions. Plasmid DNA was diluted in sterile water to a final concentration of $1 \mu \mathrm{g} / \mu \mathrm{l}$ DNA.

\section{Nonviral Gene Transfer}

Prior to transfections monolayer cultures of cells in 24-well plates were rinsed with phosphate-buffered saline (PBS, PAA) and fresh growth medium was added to the cells. For transfections with Escort III, basal medium was added instead of growth medium. For transfections with TransPass D2, growth medium was removed and the transfection complexes were directly added to the cells. All transfections were performed according to the manufacturer's instructions. Reagents were complexed to plasmid DNA in sterile polypropylene tubes at room temperature.

\section{Nanofectin 1 and 2}

Nanofectin 1 and 2 are positively charged polymers with DNA-binding capacity that are embedded into a porous nanoparticle. For transfections, $1 \mu \mathrm{g}$ DNA in $50 \mu \mathrm{l} \mathrm{NaCl}$ $(0.9 \%)$ was complexed with $3.2 \mu$ l Nanofectin 1 or 2 in $50 \mu \mathrm{l} \mathrm{NaCl}(0.9 \%)$ and added to the cells after $25 \mathrm{~min}$. Two hours later, $500 \mu \mathrm{l}$ growth medium was added to the complexes.

\section{Superfect}

This activated-dendrimer transfection reagent has a spherical architecture with branches radiating from a central core and terminating at positively charged amino groups. About $1 \mu \mathrm{g}$ DNA was diluted in Opti-MEM to a total volume of $60 \mu \mathrm{l}$. Superfect transfection reagent $(5 \mu \mathrm{l})$ was added. Complexes were allowed to form for $10 \mathrm{~min}$ and added to the cells. Two and a half hours later, the cells were washed with PBS and fresh growth medium was added.

\section{JetPEI}

JetPEI consists of a linear polyethylenimine and compacts the DNA into positively charged particles. Intracellularly, it protects the DNA from degradation in endolysosomes by buffering the endosomal $\mathrm{pH}$. The DNA $(1 \mu \mathrm{g})$ and $2 \mu \mathrm{l}$ of the JetPEI reagent were complexed in $50 \mu \mathrm{NaCl}(0.9 \%)$, left to incubate for $25 \mathrm{~min}$ and added to the cells. 


\section{Escort III}

Escort III is a cationic liposome suspension in water, composed of a polycationic lipid and a neutral lipid compound. The DNA $(0.3 \mu \mathrm{g})$ and the liposome suspension $(0.6 \mu \mathrm{l})$ were diluted in $20 \mu \mathrm{l}$ Opti-MEM, combined, allowed to form complexes for $30 \mathrm{~min}$ and then added to the wells. After $6 \mathrm{~h}$, basal medium containing $20 \%$ fetal bovine serum (FBS) was added which was replaced by growth medium after $18 \mathrm{~h}$.

\section{Gene Jammer}

This formulation of polyamine and other components in $80 \%$ ethanol was diluted in $100 \mu \mathrm{l}$ Opti-MEM and was complexed with $1 \mu \mathrm{g}$ DNA. Three hours after adding these complexes, cells were washed and incubated with growth medium. For transfections of lapine articular chondrocytes, the volume of Gene Jammer reagent was varied between 3 and $12 \mu \mathrm{l}$ (vector/DNA ratios of 3:1, 6:1, 9:1 and 12:1). Exposure times tested ranged from 3 to $7 \mathrm{~h}$.

\section{Effectene}

Effectene is a transfection system based on a non-liposomal lipid. As a first step, $0.2 \mu \mathrm{g}$ of the DNA was condensed by interaction with a specific enhancer $(1.6 \mu \mathrm{l})$ in a defined buffer at a total volume of $60 \mu \mathrm{l}$. Afterwards, a volume of $5 \mu$ of the Effectene reagent was added, complexes were allowed to form for $5 \mathrm{~min}$ and added to the cells.

\section{TransPass D2}

TransPass D2 is based on a non-lipid cationic polymer. DNA $(0.3 \mu \mathrm{g})$ was complexed with $0.8 \mu \mathrm{l}$ TransPass D2 in $300 \mu \mathrm{l}$ Opti-MEM. Growth medium was removed from the cells and the polymer/DNA complexes were added after an incubation period of $25 \mathrm{~min}$. Two and a half hours later, the transfection solution was replaced by growth medium.

\section{Metafectene}

Metafectene is a polycationic transfection reagent based on a liposome that enables destabilization of the lipid membrane within the acidic endosomal environment by repulsive electrostatic forces. In $30 \mu \mathrm{l}$ Opti-MEM each, $0.5 \mu \mathrm{g}$ plasmid DNA and $2.5 \mu \mathrm{l}$ Metafectene were diluted, combined, and then the complexes obtained were added to the cells after $20 \mathrm{~min}$. For lacZ transfections of NIH 3T3 cells, in order to evaluate the optimal transfection conditions, the volume of Metafectene ranged from 1 to $4 \mu$ l (vector/DNA ratios of $2: 1,5: 1$ or $8: 1)$.

\section{FuGENE 6}

FuGENE 6 is a proprietary, non-liposomal mixture of lipids. FuGENE 6 and $1 \mu \mathrm{g}$ of DNA were allowed to form complexes in $90 \mu \mathrm{l}$ Opti-MEM $15 \mathrm{~min}$ prior to addition to the cells. For optimization studies, the volume of FuGENE 6 per $\mu \mathrm{g}$ of DNA was varied from 1 to $4 \mu \mathrm{l}$ (exposure times were of 24,48 and $72 \mathrm{~h}$ ).

\section{Lipofectamine 2000}

Lipofectamine 2000 is a novel proprietary cationic lipid formulation. DNA $(0.8 \mu \mathrm{g})$ and Lipofectamine $2000(2 \mu \mathrm{l})$ were diluted in $50 \mu \mathrm{l}$ Opti-MEM each. After combining these solutions, the complexes were allowed to form for $20 \mathrm{~min}$ and next added to the cells. Lipofectamine 2000 was optimized for transfections of cells from fibrous dysplasia and CS-1 cells. The volume of transfection reagent varied between 1 and $3 \mu \mathrm{l}$. Vector/DNA ratios were of $1.25: 1,2.5: 1$, and 3.75:1.

\section{Dreamfect}

Dreamfect combines cationic lipids and polymers, resulting in lipopolyamines, which contain a lipophilic part and a charged polyamine moiety. Plasmid DNA $(0.5 \mu \mathrm{g})$ was complexed with $2 \mu \mathrm{l}$ Dreamfect, diluted in $50 \mu \mathrm{l}$ OptiMEM, incubated for $20 \mathrm{~min}$, and added to the cells. The transfection of lapine skeletal muscle cells was optimized using Dreamfect. Dreamfect volumes were of 2, 4, and $6 \mu \mathrm{l}$ (vector/DNA ratios of 4:1, 8:1 and 12:1).

\section{Calcium Phosphate Co-precipitates}

Calcium phosphate co-precipitates were prepared by combining $0.8 \mu \mathrm{g}$ plasmid DNA in $22 \mu \mathrm{l} 0.1 \times$ TE with $25 \mu \mathrm{l}$ of $2 \times$ HEPES buffered saline [10]. $\mathrm{CaCl}_{2}(3.1 \mu \mathrm{l}, 2 \mathrm{M})$ was carefully added to this solution and the resulting complexes were applied to the cells after 25 min of incubation.

\section{Detection of Transgene Expression}

Transgene Expression was detected at a standardized representative time point of $48 \mathrm{~h}$ after transfection. Luciferase activity using all 13 transfection systems was measured by 
chemiluminescence (Luciferase Assay System; Promega, Madison, WI) using a TECAN GENios microplate reader (TECAN, Crailsheim, Germany). Sample light units (relative light units, RLU) were recorded in duplicates within $5 \mathrm{~s}$ after addition of the substrate. Transfections using the $E$. coli lac $Z$ and the human IGF-I gene were carried out with the most effective transfection system per cell type as determined by luciferase. Efficiencies were determined by $\mathrm{X}$-gal staining for $5 \mathrm{~h}$ at $37^{\circ} \mathrm{C}$ of $l a c Z$ transfected and control cells ( $\beta$-Gal Staining Set; Roche) using a standard procedure as previously described [3]. In order to determine the production of IGF-I protein, the medium was replaced by basal medium 1 day after transfection. After $24 \mathrm{~h}$, the conditioned medium was collected and subjected to ELISA (detection limit: $0.03 \mathrm{ng} / \mathrm{ml}$; R\&D Systems, Minneapolis, MN).

\section{Statistical Analysis}

Data are expressed as mean \pm standard deviation (s.d.) of separate experiments. Luciferase transfections were independently performed three to four times ( $n=3$ wells per transfection reagent) for each cell type. Sample light units (RLU) per well were recorded in duplicate. For lacZ transfections, 3-5 independent optimization experiments were carried out ( $n=3$ wells per condition). The IGF-I transfection experiments were performed in duplicate ( $n=2$ wells per condition). ANOVA was applied to determine the significance of differences among groups. $P$ values less than 0.05 were considered significant.

\section{Results}

\section{Primary Lapine Skeletal Muscle Cells}

Out of the 13 transfection systems tested, Dreamfect and Metafectene promoted maximal transgene expression as determined by chemiluminescence $(13,013 \pm 593$ and $12,519 \pm 1,428 \mathrm{RLU}$, respectively; $P=0.73$ ) (Fig. 1) vis-avis all other reagents tested. In contrast, Escort III mediated the minimal transgene expression; 30-fold lower than Dreamfect $(435 \pm 21 \mathrm{RLU})$. Maximal gene expression was seen with $0.5 \mu \mathrm{g}$ DNA at a (v/w) Dreamfect/DNA ratio of $4: 1$, corresponding to a mean transfection efficiency of $60.8 \pm 21.2 \%$. Increasing the lipid/DNA ratio $(8: 1 ; 12: 1)$ led to decreased efficiencies. IGF-I expression levels in IGF-I-transfected cells using Dreamfect were of $142.3 \pm 7.0 \mathrm{ng} / 10^{6}$ cells $/ 24 \mathrm{~h}, 285$ fold higher than in non-transfected cells (Table 1).

\section{Primary Lapine Articular Chondrocytes}

Gene Jammer, JetPEI and calcium phosphate co-precipitates mediated the highest luciferase expression $(22,806 \pm 8,373$,
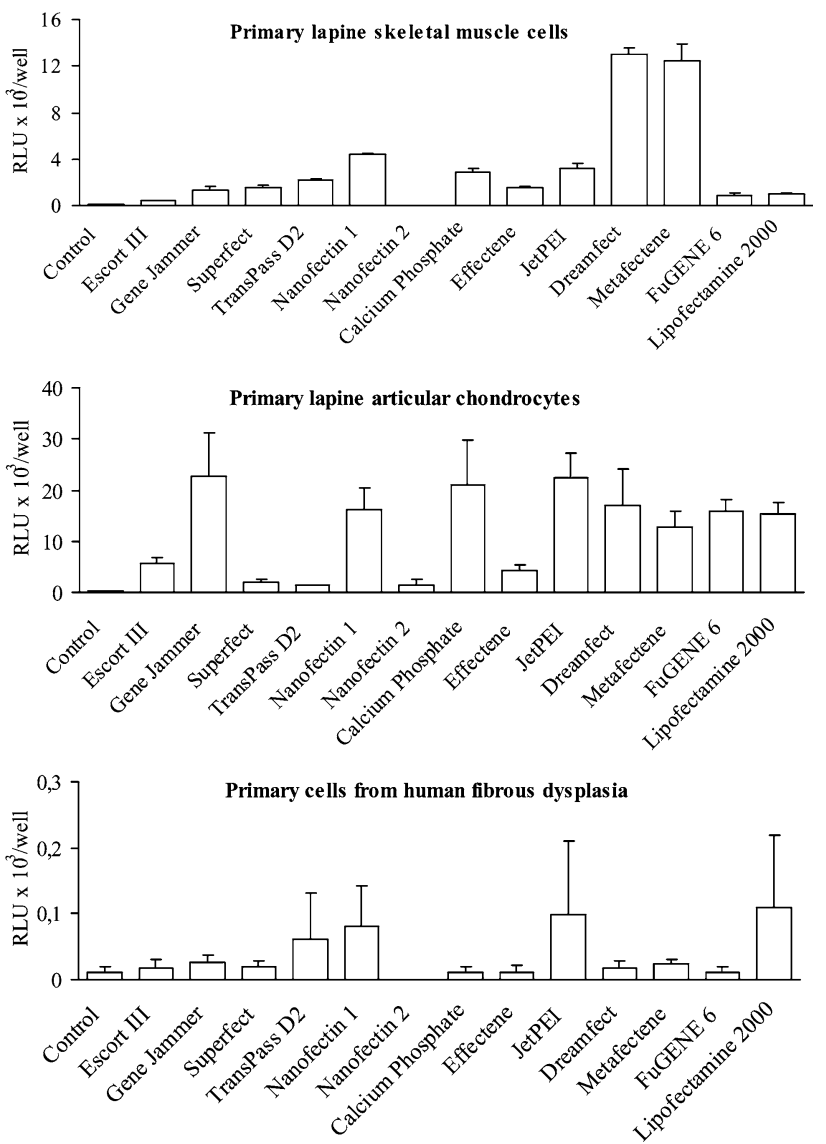

Fig. 1 Comparative analysis of transgene expression for primary cells. Data are expressed as mean luciferase activity (relative light units, RLU) per well \pm standard deviation from at least three independent experiments

$22,347 \pm 4,865$ and $21,047 \pm 8,653$ RLU; $\quad P=0.26$ ) (Fig. 1). Transfection with Nanofectin 2 resulted in the lowest efficiency $(1,296 \pm 1,214 \mathrm{RLU})$. Maximal transgene activity was obtained with $1 \mu \mathrm{g}$ DNA at a (v/w) Gene Jammer/DNA ratio of $3: 1$, corresponding to a transfection efficiency of $38.9 \pm 5.9 \%$. Increasing the lipid/DNA ratio $(6: 1$; $9: 1 ; 12: 1)$ led to decreased transfection efficiencies. Secretion of IGF-I in Gene Jammer-transfected chondrocytes was of $61.3 \pm 12.0 \mathrm{ng} / 10^{6}$ cells $/ 24 \mathrm{~h}, 77$-fold higher than in nontransfected cells $\left(0.8 \pm 0.2 \mathrm{ng} / 10^{6}\right.$ cells $\left./ 24 \mathrm{~h}\right)$.

Primary Cells from Human Fibrous Dysplasia

Lipofectamine 2000, JetPEI, Nanofectin 1, and TransPass D2 achieved highest transgene expression $(109 \pm 111$, $98 \pm 111,81 \pm 63,60 \pm 71$ RLU, respectively; $P=0.24$ ). Maximal transfection efficiency was $5.2 \pm 8.0 \%$ (Lipofectamine 2000; lipid/DNA ratio: 2.5:1). Other (3.75:1, 1.25:1) lipid/DNA ratios did not further increase 


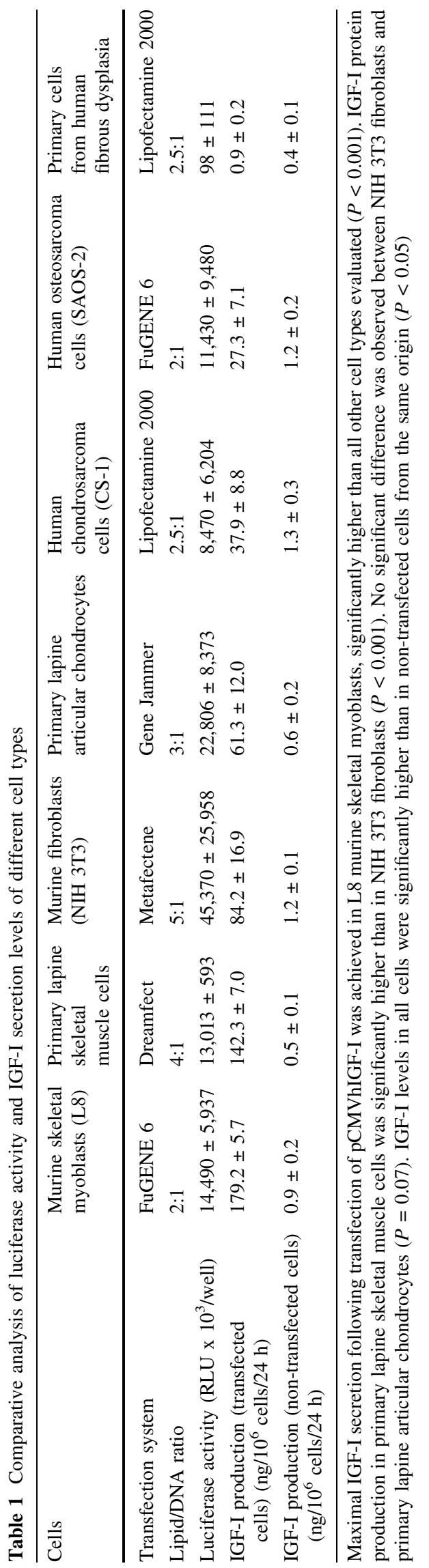

efficiencies. IGF-I secretion (Lipofectamine 2000) was 2.5fold higher than of non-transfected cells $(P<0.05)$.

\section{Human Osteosarcoma Cells (SAOS-2)}

Gene expression was maximal with FuGENE 6, JetPEI, Gene Jammer, Metafectene, Dreamfect and calcium phosphate co-precipitates $(11,430 \pm 9,480,9,426 \pm 7,887$, $9,156 \pm 6,606,8,165 \pm 4,692,6,159 \pm 4,360$ and $5,924 \pm$ 3,466 RLU, respectively; $P=0.08$ ) (Fig. 2). Highest efficiency of $12.7 \pm 16.2 \%$ was seen at a FuGENE 6/DNA ratio of $2: 1$. Ratios of $1: 1,3: 1$, and $4: 1$ did not led to further increases. IGF-I secretion was $27.3 \pm 7.1 \mathrm{ng} / 10^{6}$ cells/ $24 \mathrm{~h}, 23$-fold higher than in non-transfected cells $\left(1.2 \pm 0.2 \mathrm{ng} / 10^{6}\right.$ cells $\left./ 24 \mathrm{~h}\right)$.

\section{Human Chondrosarcoma Cells (CS-1)}

Lipofectamine 2000, Gene Jammer, Nanofectin 1, and FuGENE 6 led to the highest transgene expression $(8,470 \pm 6,204, \quad 7,482 \pm 4,575, \quad 5,354 \pm 1,188, \quad 5,197 \pm$ 2,647 RLU, respectively; $P=0.12$ ) (Fig. 2). Maximal transfection efficiency was $30.0 \pm 3.5 \%$ at a $(\mathrm{v} / \mathrm{w})$ Lipofectamine/DNA ratio of 2.5:1. Higher (3.75:1) and lower (1.25:1) ratios did not result in higher transfection efficiencies. IGF-I expression levels were of $37.9 \pm 8.8 \mathrm{ng} /$ $10^{6}$ cells/24 h, 29-fold higher than in non-transfected cells $\left(1.3 \pm 0.3 \mathrm{ng} / 10^{6}\right.$ cells $\left./ 24 \mathrm{~h}\right)$.

\section{Murine Skeletal Myoblasts (L8)}

FuGENE 6, TransPass D2 and Nanofectin 1 produced maximal transgene expression $(38,882 \pm 16,729,14,490$ $\pm 5,937, \quad 11,271 \pm 527 \mathrm{RLU}, \quad$ respectively; $\quad P=0.07$ ) (Fig. 2) with an efficiency of $64.6 \pm 14.2 \%$ (FuGENE 6). Secretion of IGF-I was $179.2 \pm 5.7 \mathrm{ng} / 10^{6}$ cells $/ 24 \mathrm{~h}$, almost 200-fold higher than in non-transfected cells (Table 1).

\section{Murine Fibroblasts (NIH 3T3)}

Luciferase expression was the highest with Metafectene and Nanofectin $1 \quad(45,370 \pm 25,958$ and 44,065 \pm 17,745 RLU, respectively; $P=0.84$ ) (Fig. 2). Maximal efficiency was $48.9 \pm 13.0 \%$ (Metafectene; lipid/DNA ratio: 5:1). Lower (2:1) or higher lipid/DNA ratios (8:1) led to decreased efficiencies. IGF-I expression levels were $84.2 \pm 16.9 \mathrm{ng} / 10^{6}$ cells $/ 24 \mathrm{~h}, 70$-fold higher than in nontransfected cells $\left(1.2 \pm 0.1 \mathrm{ng} / 10^{6}\right.$ cells $\left./ 24 \mathrm{~h}\right)($ Table 1$)$. 

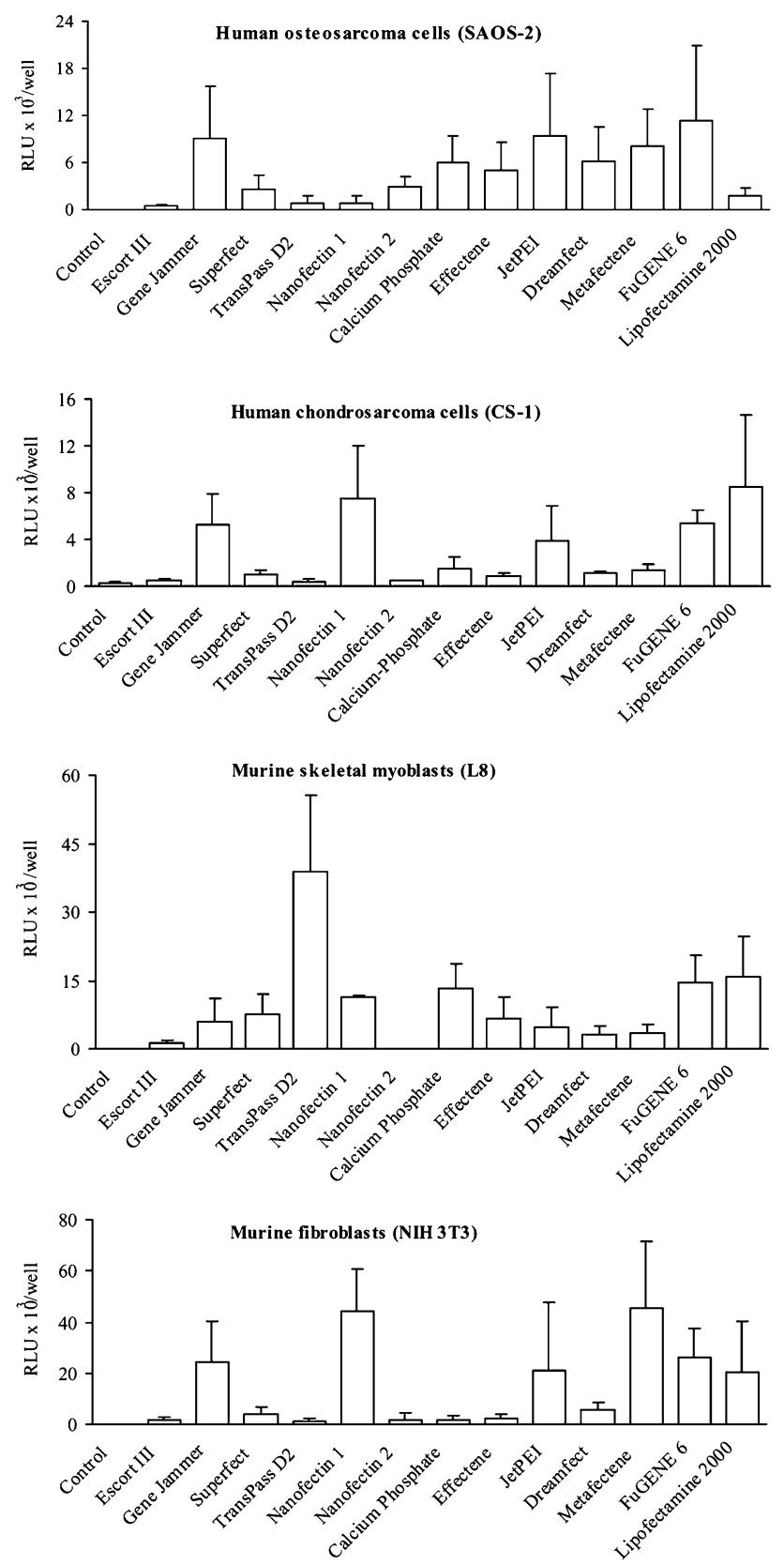

Fig. 2 Comparative analysis of transgene expression for established cell lines. Data are expressed as mean luciferase activity (relative light units, RLU) per well \pm standard deviation

\section{Discussion}

The present study comparatively analyzed the efficacy of transfection of 13 novel nonviral transfection systems in cells of musculoskeletal origin. The data indicate that relatively high levels of transfection can be achieved in primary cultures of lapine skeletal muscle cells and articular chondrocytes, as well as in established cell lines such as L8 (muscle cells), CS-1 (chondrosarcoma) and NIH 3T3 cells (fibroblasts). The data further demonstrates that human osteosarcoma (SAOS-2) cells and cells from human fibrous dysplasia can be transfected at lower efficiencies. Finally, the data suggest that significant amounts of human IGF-I, a potential therapeutic candidate, can be produced in primary lapine muscle cells and chondrocytes, L8, and NIH 3T3 cells. The results obtained using three genes (luc, lacZ, IGFI) indicate that the nature of the cell itself is a critical factor that determines the level of gene expression following transfection. Therefore, it is important to carefully characterize the most suitable transfection system for each cell type prior to functional studies in order to achieve maximal transgene expression.

Transfection efficiencies for muscle cells have been previously reported to be in the range of $0-70 \%$, e.g., using LipofectAmine and DOSPER in human myoblast clones [11], DAC-40 or Effectene in human skeletal muscle cells [12], complexes of adenovirus particles with cationic lipids and polymers in murine muscle cells [13] or Lipofectamine and DOTAP in primary cultures of murine myoblasts [14]. In the present study, efficiencies in lapine skeletal muscle cells were $61 \%$ using Dreamfect and $65 \%$ in the myoblast cell line L8 using FuGENE 6. Comparable high levels of transgene expression in a myoblast cell line have been achieved to date only using high-titer retroviral vectors [15].

The reported efficiencies in lapine articular chondrocytes of $39 \%$ using the cationic liposome formulation Gene Jammer correspond well to the $40 \%$ transfection efficiencies that were previously reported [3]. Since, the data from this study were obtained after additional treatment of the cells with hyaluronidase prior to and during transfection, it is possible that the reported transfection efficiencies may be further increased by such enzymatic treatment aimed at partially removing the extracellular matrix [3].

Transfection of primary cells from human fibrous dysplasia was difficult to achieve. Maximal efficiency was of $5.2 \%$, obtained with Lipofectamine 2000. Yet, even such relatively low efficiencies may result in possible therapeutic effects, since studies overexpressing growth factors in the arterial wall showed that efficiencies of less than $1 \%$ were sufficient to achieve a biological effect in vivo [16]. Osteosarcoma (SAOS-2) cells were transfected with an efficiency of 13\% using FuGENE 6 following optimization. Nonviral transfection of SAOS-2 cells was reported only rarely [17] and transfection efficiencies have not yet been reported to date. For human chondrosarcoma CS-1 cells, the cationic liposome Lipofectamine 2000 mediated the highest efficiencies. Comparable transfection efficiencies (30\%) using non-viral systems for this cell line and other chondrosarcoma cells have, to our best knowledge, not been demonstrated to 
date. High transfection efficiency is a basis for successful application of gene-based treatments of musculoskeletal tumors.

NIH 3T3 cells have been previously transfected with various nonviral transfection reagents, including Lipofectamine and DOSPER [18], Effectene and Superfect [19], LipofectAMINE PLUS [20] or FuGENE 6 [21]. While transfection efficiencies were less than $30 \%$ in these studies, the present data indicate that transfection efficiencies of almost $50 \%$ can be achieved with Metafectene, a cationic liposome formulation.

Interestingly, the calcium phosphate co-precipitation method promoted high transfection efficiencies in primary lapine articular chondrocytes and SAOS-2 cells, statistically not different from those mediated by commercially available reagents. With regard to its low cost and simple and reproducible production, the calcium phosphate transfection thus represents an attractive alternative.

We have selected the human IGF-I gene as an additional candidate because of potential applications in the therapy of musculoskeletal diseases. For example, IGF-I prevents muscle atrophy [22], stimulates cutaneous wound healing [23] and enhances articular cartilage repair [9, 24]. In the present study, IGF-I expression levels were between 27 and $240 \mathrm{ng} /$ $10^{6}$ cells/24 h, depending on the cell type, except for cells of fibrous dysplasia. Transfections of lapine articular chondrocytes resulted in IGF-I production of $61 \mathrm{ng} / 10^{6}$ cells $/ 24 \mathrm{~h}$, i.e. 7-fold higher than the $8.3 \mathrm{ng} / 10^{6}$ cells/ $24 \mathrm{~h}$ previously reported for bovine articular chondrocytes [25]. In L8 cells, FuGENE 6 mediated the highest transfection efficiency (65\%) and maximal IGF-I production $\left(179.2 \pm 5.7 \mathrm{ng} / 10^{6}\right.$ cells/ $24 \mathrm{~h}$ ) among all the transfection systems used. A bovine mammary epithelial cell line secreted $9.2 \mathrm{ng}$ IGF-I/10 6 cells/ $24 \mathrm{~h}$ following selection for cells carrying the transgene [26]. Retroviral gene transfer and selection of transduced cells resulted in $56 \mathrm{ng}$ IGF-I/ $10^{6}$ keratinocytes/24 h [27]. These data show that cells from different musculoskeletal origin can be transfected with optimized systems to produce significant amounts of a secreted recombinant protein that are sufficient to mediate a therapeutic effect $[9,24,25]$.

Taken together, our results indicate that novel lipidbased methods can be sufficiently optimized to offer a feasible approach for gene delivery into a wide range of cells. The described techniques might be of potential value for functional gene analyses and for gene therapy approaches in tissue engineering and the treatment of musculoskeletal disorders.

Acknowledgments We thank L. Weissbach and F. Hornicek for providing the CS-1 cells, V. Flockerzi for the NIH 3 T3 cells and Y. Mehraein for providing the SAOS-2 cells. H. Madry and M. Cucchiarini have been supported by grants from the Deutsche Forschungsgemeinschaft (DFG MA 2363/1-3 and DFG CU 55/1-3).

\section{References}

1. Evans, C. H., Ghivizzani, S. C., Herndon, J. H., \& Robbins, P. D. (2005). Gene therapy for the treatment of musculoskeletal diseases. Journal of the American Academy of Orthopaedic Surgeons, 13, 230-242.

2. Luo, D., \& Saltzman, W. M. (2000). Synthetic DNA delivery systems. Nature Biotechnology, 18, 33-37.

3. Madry, H., \& Trippel, B. (2000). Efficient lipid-mediated gene transfer to articular chondrocytes. Gene Therapy, 7, 286-291.

4. Pampinella, F., Lechardeur, D., Zanetti, E., MacLachlan, I., Benharouga, M., Lukacs, G. L., \& Vitiello, L. (2002). Analysis of differential lipofection efficiency in primary and established myoblasts. Molecular Therapy, 5, 161-169.

5. Hudde, T., Rayner, S. A., Comer, R. M., Weber, M., Isaacs, J. D., Waldmann, H., Larkin, D. F., \& Gearge, A. J. (1999). Activated polyamidoamine dendrimers, a non-viral vector for gene transfer to the corneal endothelium. Gene Therapy, 6, 939-943.

6. Chemin, I., Moradpour, D., Wieland, S., Offensperger, W. B., Walter, E., Behr, J. P., \& Blum, H. E. (1998). Liver-directed gene transfer: A linear polyethlenimine derivative mediates highly efficient DNA delivery to primary hepatocytes in vitro and in vivo. Journal of Viral Hepatitis, 5, 369-375.

7. Templeton, N. S., \& Lasic, D. D. (1999). New directions in liposome gene delivery. Molecular Biotechnology, 11, 175-180.

8. Ravi Kumar, M., Hellermann, G., Lockey, R. F., \& Mohapatra, S. S. (2004). Nanoparticle-mediated gene delivery: State of the art. Expert Opinion on Biological Therapy, 4, 1213-1224.

9. Madry, H., Kaul, G., Cucchiarini, M., Stein, U., Zurakowski, D., Remberger, K., Menger, M. D., Kohn, D., \& Trippel, S. B. (2005). Enhanced repair of articular cartilage defects in vivo by transplanted chondrocytes overexpressing insulin-like growth factor I (IGF-I). Gene Therapy, 12, 1171-1179.

10. Graham, F. L., \& van der Erb, A. J. (1973). A new technique for the assay of infectivity of human adenovirus 5 DNA. Virology, 52, 456-467.

11. Albert, N., \& Tremblay, J. P. (1992). Evaluation of various gene transfection methods into human myoblast clones. Transplantation Proceedings, 24, 2784-2786.

12. Endesfelder, S., Bucher, S., Kliche, A., Rezska, R., \& Speer, A. (2003). Transfection of normal primary human skeletal myoblasts with p21 and p57 antisense oligonucleotides to improve their proliferation: A first step towards an alternative molecular therapy approach of Duchenne muscular dystrophy. Journal of Molecular Medicine, 81, 355-362.

13. Dodds, E., Dunckley, M. G., Naujoks, K., Michaelis U., \& Dickson, G. (1998). Lipofection of cultured mouse muscle cells: A direct comparison of Lipofectamine and DOSPER. Gene Therapy, 5, 542-551.

14. Trivedi, R. A., \& Dickson, G. (1995). Liposome-mediated gene transfer into normal and dystrophin-deficient mouse myoblasts. Journal of Neurochemistry, 64, 2230-2238.

15. el Oakley, R. M., Brand, N. J., Burton, P. B., Cullen, M. C., Adams, G. B., Poznansky, M. C., Barton, P. J., \& Yacoub, M. H. (1998). Efficiency of a high-titer retroviral vector for gene transfer into skeletal myoblasts. Journal of Thoracic and Cardiovascular Surgery, 115, 1-8.

16. Nabel, E. G., Yang, Z. Y., Plautz, G., Forough, R., Zhan, X., Haudenschild, C. C., Maciag, T., \& Nabel, G. J. (1993). Recombinant fibroblast growth factor-1 promotes intimal hyperplasia and angiogenesis in arteries in vivo. Nature, 362, 844-846.

17. Marcellus, R. C., Teodoro, J. G., Charbonneau, R., Shore, G. C., \& Branton, P. E. (1996). Expression of p53 in Saos-2 osteosarcoma cells induces apoptosis which can be inhibited by Bcl-2 or 
the adenovirus E1B-55 kDa protein. Cell Growth and Differentiation, 7, 1643-1650.

18. Marit, G., Cao, Y., Froussard, P., Ripoche, J., Dupouy, M., Elandaloussie, A., Lacombe, F., Mahon, F. X., Keller, H., Pla, M., Reiffers, J., \& Theze, J. (2000). Increased liposome-mediated gene transfer into haematopoietic cells grown in adhesion to stromal or fibroblast cell line monolayers. European Journal of Haematology, 64, 22-31.

19. Weiskirchen, R., Kneifel, J., Weiskirchen, S., van de Leur, E., Kunz, D., \& Gressner, A.M. (2000) Comparative evaluation of gene delivery devices in primary cultures of rat hepatic stellate cells and rat myofibroblasts. BMC Cell Biol,1, 4.

20. Akita, H., Ito, R., Khalil, I. A., Futaki, S., \& Harashima, H. (2004). Quantitative three-dimensional analysis of the intracellular trafficking of plasmid DNA transfected by a nonviral gene delivery system using confocal laser scanning microscopy. Molecular Therapy, 9, 443-451.

21. Hellgren, I., Drvota, V., Pieper, R., Enoksson, S., Blomberg, P., Islam, K. B., \& Sylvén, C. (2000). Highly efficient cell-mediated gene transfer using non-viral vectors and FuGene6: In vitro and in vivo studies. Cellular and Molecular Life Sciences, 57, 1326-1333.

22. Schakman, O., Gilson, H., de Coninck, V., Lause, P., Verniers, J., Havaux, X., Ketelslegers, J. M., \& Thissen, J. P. (2005). Insulinlike growth factor-I gene transfer by electroporation prevents skeletal muscle atrophy in glucocorticoid-treated rats. Endocrinology, 146, 1789-1797.

23. Jeschke, M. G., Herndon, D. N., Baer, W., Barrow, R. E., \& Jauch, K. W. (2001). Possibilities of non-viral gene transfer to improve cutaneous wound healing. Current Gene Therapy, 1, 267-278.

24. Gelse, K., von der Mark, K., Aigner, T., Park, J., \& Schneider, H. (2003). Articular cartilage repair by gene therapy using growth factor-producing mesenchymal cells. Arthritis and Rheumatism, $48,430-441$.

25. Madry, H., Zurakowski, D., \& Trippel, S. B. (2001). Overexpression of human insulin-like growth factor-I promotes new tissue formation in an ex vivo model of articular chondrocyte transplantation. Gene Therapy, 8, 1443-1449.

26. Romagnolo, D., Akers, R. M., Wong, E. A., Boyle, P. L., McFadden, T. B., \& Turner, J. D. (1992). Overexpression of ovine insulin-like growth factor-I stimulates autonomous autocrine or paracrine growth in bovine mammary-derived epithelial cells. Molecular Endocrinology, 6, 1774-1780.

27. Eming, S. A., Snow, R. G., Yarmush, M. L., \& Morgan, J. R. (1996). Targeted expression of insulin-like growth factor to human keratinocytes: Modification of the autocrine control of keratinocyte proliferation. Journal of Investigative Dermatology, 107, 113-120. 